\title{
O MITO DA ORIGEM DE SERÁPIS REVISITADO
}

\author{
Rogério Sousa $^{1}$
}

\section{Resumo}

Apesar do impacto que o culto de Serápis teve no mundo helenístico, as origens do seu culto permanecem pouco conhecidas. Neste artigo, confrontamos as referências às origens do deus, as quais sugerem uma proveniência alóctone do culto, com os dados decorrentes da etimologia e iconografia, as quais apontam claramente para uma origem autóctone do culto de Serápis.

Palavras-chave: Serápis, Sakara, Alexandria

\begin{abstract}
Despite the impact of the cult of Sarapis in the Hellenistic world, the origins of his cult remain unclear. In this article we put in contrast the references allusive to the origins of the god, which suggest a foreign origin of the cult, with those relative to the etymology, iconography and cult of the god, the later pointing out to an autochthonous origin of the cult of the Sarapis.
\end{abstract}

Keywords: Sarapis, Saqqara, Alexandria

\footnotetext{
${ }^{1}$ Rogério Sousa é Doutor em História Antiga pela Universidade do Porto - Portugal e é Investigador Integrado do Centro de Estudos Clássicos e Humanísticos da Universidade de Coimbra - Portugal.
} 
A fundação formal do culto de Serápis ocorreu entre os reinados de Ptolemeu I Sóter e Ptolemeu II Filadelfo, sensivelmente entre 306 a.C. e 282 a.C., e constituiu um poderoso instrumento político que os primeiros soberanos Lágidas souberam utilizar para congregar, sob o seu domínio, uma população heterogénea e multicultural constituída majoritariamente por egípcios e gregos, mas em que também os judeus desempenhavam um papel importante. A difusão e a penetração do culto, tanto em Alexandria como em todo o mundo helenístico, indiciam, no entanto, que estamos perante um fenómeno que transcende largamente a esfera política. O sucesso do culto estava alicerçado na consistência, no alcance e no significado da mensagem filosófico-teológica que lhe estava associada.

Um dos aspectos mais intrigantes do culto de Serápis diz respeito à própria proveniência do culto. Segundo a lenda veiculada pelos autores clássicos, não há dúvida de que Serápis era uma divindade asiática, originária de Sinope, no mar Negro, e revelou-se em sonhos a Ptolemeu I. Na sequência do sonho, o fundador da dinastia ptolemaica teria trazido a sua estátua para o Egipto para o tornar no deus tutelar de Alexandria. No tratado Isis e Osíris, Plutarco descreve o acontecimento do seguinte modo:

\footnotetext{
Ptolemeu Sóter viu em sonhos o colosso de Plutão que estava em Sinope: ignorava a sua existência, não conhecendo a sua forma e nunca o tinha visto antes. Nesta visão, o colosso ordenou-lhe que transportasse o mais depressa possível esta gigantesca figura para Alexandria. Ptolemeu, que ignorava o lugar em que se erigia, ficou em apuros, e ao contar a sua visão aos seus amigos, encontrou entre eles um homem chamado Sosíbio, que tinha visto um colosso parecido ao que o rei tinha visto no seu sonho. Então Ptolemeu enviou Sóteles e Dioniso, e estes homens, depois de muitas vicissitudes e longo tempo, apesar de contarem com a ajuda da divina providência, conseguiram levar furtivamente o colosso. Assim que foi vista aquela figura transportada, Timóteo e Manéton, o Sebenita, conjecturaram por meio de Cérbero e o dragão que possuía por emblemas, que se tratava de uma estátua de Plutão, e persuadiram Ptolemeu de que não representava outro deus a não ser Serápis. Do lugar donde vinha não usava certamente esse nome, mas uma vez transportado para Alexandria designou-se assim, uma vez que recebeu dos egípcios o nome de Serápis, que é precisamente o que utilizam para designar Plutão (PLU. Isis e Osíris, 28).
}

O relato de Plutarco é interessante por várias razões. Em primeiro lugar, o texto documenta o debate intercultural em torno da identidade do deus. Desde logo, é importante sublinhar o carácter inominado deste "deus desconhecido". O deus não revela a sua identidade, a qual é vaticinada pelo parecer de dois sábios alexandrinos que personificam as duas tradições esotéricas, a egípcia e a grega. São mencionados Timóteo, membro dos Eumólpidas, a família à qual pertenciam os hierofantes dos mistérios eleusinos, e Manéton, sacerdote de Heliópolis de origem sebenita. Os sábios concordam que o deus representado no colosso é Plutão (ou Hades) que «recebeu dos egípcios o nome de Serápis, que é precisamente 
o que utilizam para designar Plutão». A fundação do culto de Serápis assentava, portanto, num diálogo intercultural - podemos mesmo falar de bilinguismo cultural - que se manifestou desde logo na criação de um culto familiar tanto para egípcios como para gregos. O facto é que o estatuto universal do deus manifestou-se, desde logo, na sua capacidade para estabelecer identificações sincréticas com outros deuses, quer estes fossem gregos, como era o caso de Hades, Zeus ou Dionísio ou egípcios, como Osíris ou Ápis.

A referência a Sinope é intrigante, já que, embora seja habitualmente situada na Ásia Menor, pode na realidade ser evocativa da colina do Sinopeión, onde se implantava o Serapeum de Sakara. É, de resto, o próprio Plutarco que assevera a origem egípcia do culto de Serápis, mencionando certas fontes que lhe asseguravam que o nome do deus alexandrino designava afinal o «féretro de Ápis» (PLU. Isis e Osiris, 29); o que actualmente sabemos ser verdade. Até para os autores clássicos, Serápis tinha, portanto, uma origem autóctone.

É justamente esta origem local que nos é apresentada por pseudo-Calístenes no Romance de Alexandre. Alexandre, ao encontrar uma estátua do deus, reconheceu a presença de Serápis como deus omnisciente que protegia a cidade. Para reavivar o seu culto, mandou erguer um altar - mais tarde conhecido como o grande altar de Alexandre - onde terá conduzido um sacrifício inaugural acompanhado por uma oração: «Tu és o deus que governa esta terra, cujo olhar se estende pelo mundo infinito». Uma águia, simbolizando o poder real, voou, então, sobre o altar, arrebatando um pedaço das entranhas aí depositadas e levou-o para um antigo recinto templário, onde, mais tarde, se elevaria o Serapeum alexandrino. Aí, Alexandre encontrou uma estátua divina entronizada que acariciava com a mão direita um animal multiforme empunhando um ceptro com a mão esquerda, atributos por meio dos quais facilmente se entrevê o vulto inominado de Serápis. O deus estava acompanhado por uma virgem e o culto de ambos havia aí sido estabelecido por Sesóstris (Senuseret em egípcio)².

Curiosamente também Arriano associa Alexandre a Serápis, mas desta feita, situa esta ligação na Babilónia, pouco antes da morte do soberano macedónio:

Narram também as Efemérides Reais que Píton, Átalo, Demofonte, Pucestas e Cleómenes, Menidas e Seleuco estiveram de guarda toda a noite no templo de Serápis para perguntar ao deus se era conveniente e melhor trazer Alexandre ao templo da divindade e suplicar ao deus pela sua cura. A resposta do deus fora,

\footnotetext{
${ }^{2}$ Silva (2013).
} 
todavia, que não o deslocassem ao templo, sendo "melhor" que permanecesse onde estava (ARRIANO, VII, 26, 2) ${ }^{3}$.

Esta referência tem sido um dos principais argumentos para defender a origem estrangeira do culto, já que Serapsi era justamente um dos títulos divinos do deus Enki, significando "rei das profundezas". Tal como no relato de Plutarco, que associa o deus inominado a Serápis e a Plutão, a narrativa de Arriano coloca em evidência outra manifestação babilónica do deus. Mais do que uma origem babilónica do deus, o que o relato documenta é a associação o culto de Serápis à morte de Alexandre. Os relatos de Arriano e o de pseudo-Calístenes apresentam-nos momentos da vida e da morte de Alexandre em que a presença divina de Serápis já se manifesta. O vulto de Alexandre confundia-se, portanto, com o de Serápis e, dessa forma, a simbiose insinuada entre ambos adensava a carga simbólica dos principais lugares sagrados de Alexandria: através deles insinuava-se o perfil de Alexandre no Serapeum alexandrino (no relato de pseudo-Calístenes) e, inversamente, a presença de Serápis no Soma onde repousavam os restos mortais de Alexandre (no relato de Arriano). Tais relatos não conflituam com a fundação do culto de Serápis por Ptolemeu Sóter, antes o reforçam, por meio da intensidade da relação pessoal que se manifestava entre Alexandre e o deus inominado ${ }^{4}$.

As narrativas clássicas da origem do culto parecem mais empenhadas em sublinhar a associação de Alexandre ao culto de Serápis do que propriamente em identificar uma origem alóctone.

Narrativas etiológicas à parte, a análise dos atributos de Serápis aponta claramente para uma origem egípcia do deus. As pistas para a origem puramente egípcia do culto de Serápis conduzem-nos a Mênfis onde, desde a fundação da monarquia faraónica (c. 3000 a.C.), se prestava um culto importante ao touro Ápis (Hap, em egípcio, lit. "corrente”, termo conotado com o movimento da cheia do Nilo). Estas conotações à cheia detectam-se também nos autores clássicos. Plutarco assevera que:

Mais razoáveis são aqueles que afirmam que o nome de Serápis, ao derivar de seústhai e de sousthain, precipitar-se, lançar-se, exprime o movimento que anima o conjunto do mundo universal (PLU. Isis e Osíris, 29).

\footnotetext{
${ }^{3}$ Cf. Sales (2005: 106).

${ }^{4} \mathrm{O}$ modelo arquetípico para uma tal identificação entre Alexandre e Serápis remontava à própria tradição faraónica onde o rei morto se identificava com Osíris. Afinal, como refere Plutarco, «Serápis é o nome comum aplicado a todos quantos sofrem esta mudança (morte), da mesma forma de Osíris» (PLU, Ísis e Osíris, 28).
} 
Certo é que tradicionalmente o touro Ápis encarnava a potência viril do faraó reinante e era tido como o $b a$ (poder divino) do deus Ptah, o deus supremo que presidia sobre a cidade de Mênfis e que, desde a fundação da monarquia, personificava o alcance universal da monarquia faraónica ${ }^{5}$. Sabemos, por fontes historiográficas, que Alexandre sacrificou-se diante do touro Ápis, num gesto político que pretendia afirmar o respeito pelas tradições locais, mas que deve também ser visto como o ponto de partida para a definiçãa do culto helenístico de Serápis ${ }^{6}$. Na verdade, embora sem qualquer relevo para os autores clássicos, este gesto de Alexandre documenta eloquentemente todo o movimento intercultural subsequente que irá enformar e informar o culto alexandrino de Serápis.

Eleito por um conjunto de sinais distintivos, o touro Ápis era cultuado como uma imagem viva de Ptah no próprio recinto do deus menfita. O touro divino participava em cerimónias reais, sobretudo por ocasião da coroação e do $\mathrm{Heb} \mathrm{Sed}^{7}$, normalmente numa corrida ritual em que era acompanhado pelo faraó. A fertilidade e força do touro sagrado simbolizavam o poder e a vitalidade do próprio faraó. Toda a existência destes touros estava rodeada por um profundo sentido de sacralidade. Instalado no magnífico templo de Ptah, o touro sagrado detinha domínios privados onde vivia com um harém de vacas e passeava-se num pátio sagrado especialmente preparado para o efeito em que os peregrinos acorriam em grande número em busca de sinais oraculares ${ }^{8}$. Após a sua morte, era decretado um luto nacional que se prolongava por setenta dias, ao longo dos quais o touro sagrado era cuidadosamente mumificado. Sintomático da grande importância deste processo é o recinto descoberto no complexo sagrado de Ptah, onde se encontravam magníficas e monumentais mesas de embalsamamento talhadas em alabastro especialmente confeccionadas para a mumificação dos touros sagrados. Na sequência deste processo, o touro identificava-se com Osíris, o deus dos mortos, passando, então, a ser designado Osir-Hap, ou seja, «Ápis defunto». É esta manifestação funerária que está na base da designação helenizada, Serápis, difundida no mundo greco-romano, como assevera o próprio Plutarco:

\footnotetext{
${ }^{5}$ Sousa (2011: 165). Cf. também Acúrcio (2001: 81-82).

${ }^{6}$ Rodrigues (2001: 46).

${ }^{7}$ Cerimonial de regeneração do poder real celebrado, em teoria, trinta anos após a coroação do monarca.

${ }^{8}$ Bagnall, Rathbone (2004: 97).
} 
A maior parte dos egípcios estima que este nome (Serápis) é composto pelos de Osíris e de Ápis, estabelecendo assim, e querendo ensinar-nos que, em Ápis, se deve ver uma bela imagem da alma de Osíris (PLU. Isis e Osíris, 29).

A identificação entre Osíris e Serápis decorre, portanto, da manifestação funerária do touro Ápis e não da sua origem directa no culto de Osíris. Na verdade, na expressão Osir-Hap, o termo «Osíris» é usado como um título e não para designar especificamente o deus Osíris. $\mathrm{Na}$ tradição funerária egípcia, Osíris era efectivamente um título genérico que se aplicava indiferenciadamente a uma divindade funerária, mais especificamente a um defunto justificado. É justamente esse facto que está na base da mesma utilização do nome de Serápis no contexto alexandrino. Como assevera Plutarco, «Serápis é o nome comum aplicado a todos quantos sofrem esta mudança (morte), da mesma forma de Osíris» (PLU. Ísis e Osíris, 28).

O touro embalsamado era visto como uma manifestação de Osir-Hap, ou seja, uma manifestação funerária de Ápis. A morte do touro sagrado e a sua subsequente mumificação e regeneração eram vistas como um mistério profundo, que assinalava o triunfo sobre a morte e indicava o caminho a seguir para conquistar a imortalidade.

Uma vez preparada a múmia do touro, era chegado o momento de a transportar para a necrópole. A múmia era colocada numa barca sagrada, para vencer o lago que conduzia à necrópole. Aí, seria o touro sepultado nas galerias subterrâneas do Serapeum ou «Morada de Ápis», como era designado em demótico ${ }^{9}$. Escavadas e ampliadas na Época Greco-Romana, as grandes galerias do Serapeum de Sakara albergaram várias gerações destas encarnações taurinas, que emanavam para o Egipto a potência fecundadora do deus primordial, Ptah.

O Serapeum de Sakara era um local da mais alta importância religiosa. Para ele confluía um grande número de visitantes de todas as proveniências e vivia-se aí uma intensa atmosfera multicultural ${ }^{10}$. É forçoso salientar que, ainda antes da ocupação macedónica, se constituíra aí uma comunidade multicultural que combinava os elementos autóctones expressos em demótico (o último estádio de evolução da língua egípcia), com aqueles derivados da cultura grega, cujo peso já era importante. Com toda a probabilidade, foi entre esta comunidade de sábios do próprio Serapeum menfita que se gerou, de modo espontâneo e

\footnotetext{
${ }^{9}$ Bagnall, Rathbone (2004: 100).

${ }^{10}$ Durante o período ptolemaico, Mênfis foi dividida em quarteirões étnicos, cada um deles tendo por centro o templo respectivo. Entre estes contava-se, pela sua antiguidade, o bairro «Fenício» que venerava a deusa Astarte e o bairro «Grego», constituído por descendentes de militares gregos que se instalaram no Delta. Bagnall, Rathbone (2004: 98). Eloquentes exemplos do ambiente multicultural da necrópole menfita no período ptolemaico são também descritos em Chauveau (2000: 128-140).
} 
sem preocupações políticas de peso, a matriz de crenças e do culto que, mais tarde, havia de ser capitalizada pelos soberanos Lágidas e transformar-se no culto alexandrino de Serápis.

A origem do culto de Serápis enraíza-se nesta manifestação funerária do deus Ptah. A influência do culto menfita do touro sagrado Osir-Hap irá perdurar mesmo após a helenização do culto de Serápis. A manifestação taurina de Ápis permanecerá sempre um traço fundamental da iconografia de Serápis, sobretudo quando se pretendia evidenciar os seus poderes ctónicos e o mistério da sua regeneração no mundo inferior. No próprio Serapeum de Alexandria, o deus era representado na sua manifestação taurina nas galerias subterrâneas, certamente de modo complementar à sua representação humana que era cultuada no templo propriamente dito. Também nos locais de culto espalhados pelo mundo romano, a iconografia taurina do deus se manteve, sempre conotada com o mistério da regeneração da luz, como o Serapeum da Vila Adriana ilustra exemplarmente.

Não obstante, a caracterização helenista de Serápis transcende em larga medida esta manifestação taurina, pelo que é importante detectar outras fontes egípcias para a caracterização do deus. De todas as influências possíveis, é no próprio culto menfita do deus Ptah que encontramos a melhor e mais completa correspondência com o culto helenístico de Serápis. Embora esta relação tenha permanecido praticamente insuspeita, a verdade é que Ptah, o deus supremo cultuado em Mênfis, apresenta todos os aspectos da definição divina do deus alexandrino e foi seguramente aquele antiquíssimo deus egípcio que forneceu o essencial da matriz teológica que guindou Serápis ao estatuto de deus universal. Em primeiro lugar, Ptah, o «Belo de rosto», tal como era evocado num dos seus mais conhecidos epítetos, personificava o soberano da criação, por excelência. A sua barba divina, larga e rectangular, é um atributo único entre os deuses egípcios e constitui um símbolo de soberania e era, como tal, usada unicamente pelo faraó. Como um deus ctónico, Ptah era um deus do mundo inferior e nessa qualidade era cultuado como o provedor do povo do Egipto. O deus presidia à fertilidade da terra, ao crescimento da vegetação - um dos seus epítetos era justamente o «celeiro de Tatenen» ou, em tradução livre, «celeiro da colina primordial». O carácter ctónico conferia-lhe poder sobre os tesouros minerais e, muito em particular, sobre as riquezas auríferas. A extracção das riquezas do mundo inferior, como o ouro e as pedras semipreciosas, estava, assim, sob a sua tutela, bem como o subsequente trabalho artesanal. Mas, acima de tudo, Ptah era o deus supremo, pré-existente à criação, criador de todas as coisas vivas, deus incriado, que concebeu o mundo na sua mente (coração) e o enunciou pela palavra por meio da sua língua. Ptah era, em suma, o pilar cósmico, o poder de luz que unia o céu e a terra. 
A definição egípcia de Ptah corresponde, ponto por ponto, à caracterização helenística de Serápis, estando certamente na base das suas reputadas prerrogativas de cosmocrator, soberano universal, deus da fertilidade, dos infernos, mas também da luz e do Logos criador. Portanto, é na própria caracterização egípcia de Ptah que encontramos a chave para compreender os posteriores movimentos de identificação sincrética com cultos helenísticos de Zeus, Hades, Dioniso e até de Hélio, facto que devemos ter em mente para balizar a plasticidade do culto de Serápis.

O culto de Osíris, embora claramente em segundo plano quando comparado com o culto de Ptah, não está totalmente ausente da matriz egípcia de Serápis. Seguindo uma tendência que se verificou um pouco por todo o Egipto, o culto de Osíris foi-se enraizando na necrópole menfita, sobretudo a partir do período ramséssida (1295-1069 a.C. $)^{11}$. A inscrição da Pedra de Chabaka (716-702 a.C.) dá-nos, a este respeito, um claro testemunho, evocando o resgate do cadáver de Osíris na necrópole menfita, para permanecer resguardado pela escolta de Ptah-Tatenen ${ }^{12}$. A razão para a extraordinária difusão do culto de Osíris por todo o Egipto residia na visão salvífica do Além que emanava do triunfo de Osíris sobre a morte: por meio de um comportamento ético, cada um podia almejar a ser eleito como um justo no tribunal de Osíris e, assim, conquistar a imortalidade, transformando-se num deus. A força deste imaginário foi tal que o culto de Osíris se implantou em todas as principais necrópoles do país, criando sincretismos com os deuses locais. Em Sakara, a necrópole de Mênfis, Osíris foi integrado nos cultos locais pelos deuses Osir-Hap e também, sobretudo a partir da Época Baixa, de Ptah-Sokar-Osíris, uma divindade compósita que conheceu uma difusão notável na necrópole menfita. Esta divindade resultava da confluência de três deuses ctónicos: Ptah personificava os poderes regeneradores da terra, Sokar (o deus falcão da necrópole menfita) simbolizava o poder de luz que renascia no mundo inferior, enquanto Osíris simbolizava a ressurreição proporcionada aos justos no Além. Reuniam-se, assim, num único deus, várias noções teológicas que até aí se haviam desenvolvido autonomamente entre si, atestando um movimento de sincretismo crescente característico da teologia egípcia do I milénio a.C.

\footnotetext{
${ }^{11}$ Modelo mítico do rei bom e civilizador, Osíris foi, segundo o mito, assassinado pelo irmão Set, deus do deserto que encarnava as forças do caos. Retalhando o corpo do irmão, Set espalhou os seus pedaços por todo o Egipto. Ísis, esposa e irmã de Osíris, recolheu-os piedosamente e, com a força da magia e do amor, confeccionou a primeira múmia: por meio dela Osíris ressuscitava e tornava-se rei do mundo inferior onde presidia sobre o tribunal dos mortos e garantia a reposição da justiça.

${ }^{12}$ Pedra de Chabaka, 64 (SOUSA 2011: 69).
} 
Antes mesmo de se helenizarem e de inaugurarem um movimento de sincretismo multicultural com outras divindades do mundo grego, os cultos de Ptah, de Ápis e de PtahSokar-Osiris haviam já criado, com os próprios cultos autóctones, uma matriz teológica sincretista. É, portanto, esta matriz sincrética que está na base da afirmação universalista de Serápis no contexto alexandrino.

Nem a própria associação de Serápis a Ísis - que em grande medida é responsável pelo excessivo peso que a identificação entre Serápis e Osíris possui actualmente - decorre especificamente da constelação mitológica de Osíris. Na Época Greco-Romana, o culto de Ísis estava solidamente implantado na região menfita, assim como o de Hathor, e ambos sobrepunham-se largamente ao culto local da deusa leonina Sekhmet - que, tradicionalmente, era tida como a divindade parédre de Ptah. Reflexo da importância crescente de Ísis no território menfita é a identificação das vacas que davam à luz o touro Ápis com a deusa Ísis, sendo - também elas - alvo de um culto especial e de um enterramento próprio, neste caso o Iseum, escavado num dos uadis vizinhos ao Serapeum de Sakara.

Do mesmo modo, também Hórus, o filho divino de Ísis e Osíris, foi integrado na tríade alexandrina de Serápis sob a designação de Harpócrates (expressão grega que deriva da forma egípcia, Horpakhered, que significa «Hórus criança») e reflecte a mesma implantação da constelação divina de Osíris entre os cultos menfitas. Já na Pedra de Chabaka, a grande obra da criação empreendida por Ptah convergia para a entronização de Hórus, que personificava simultaneamente o faraó reinante e o coração vivo do deus supremo ${ }^{13}$.

Em todas as suas dimensões, a teologia tardia de Mênfis preparava os fundamentos que iriam abrir o caminho para a formulação de Serápis como um deus da fertilidade, do mundo inferior, mas também como um criador da luz e do mundo por meio do poder da palavra e, nesse aspecto, constituía já uma tradição precursora da noção do Logos - a mente divina que preside aos seres -, que seria tão amplamente celebrada pela tradição filosófica alexandrina ${ }^{14}$. Extraídas dos velhos textos hieroglíficos e hieráticos, formuladas em demótico, estas noções foram certamente traduzidas para o grego desde cedo, ainda antes da ocupação macedónica, originando, assim, um caudal de reflexão que, ao tempo da fundação da dinastia ptolemaica, estava já em claro florescimento e que, no ambiente multicultural alexandrino, iria atingir o seu pleno amadurecimento.

\footnotetext{
${ }^{13}$ Sousa (2011: 69;98).

${ }^{14}$ Sousa (2011: 168-172).
} 
É possível que tenha sido o próprio Serapeum de Sakara, então já povoado por uma comunidade multicultural, que tenha proporcionado a inspiração aos primeiros soberanos Lágidas, para criar um culto multicultural, e universal, socorrendo-se, para isso, de um matriz teológica simultaneamente bem enraizada nas tradições locais - portanto susceptível de uma fácil aceitação - e ao mesmo tempo excepcionalmente propensa a novas sínteses, o que conferia um enorme potencial político ao culto.

O resultado final deste extraordinário labor concretizou-se no culto alexandrino de Serápis. A narrativa etiológica transmitida por Plutarco explica a aparência helenística do belo colosso de Serápis, que se erguia no Grande Serapeum de Alexandria, atribuído ao escultor ateniense Briáxis ${ }^{15}$. À iconografia grega do deus foi associada a tradição sincrética autóctone expressa em demótico. Seria este núcleo que, uma vez traduzido para a língua grega, constituiria, afinal, a inovação dos cultos alexandrinos no Helenismo. Esta consistência interna que advinha de um longo e milenar processo de maturação seria afinal o segredo para o tremendo sucesso que estes cultos iriam conhecer em todo o mundo mediterrânico.

${ }^{15} \mathrm{O}$ famoso escultor trabalhara no mausoléu de Halicarnasso, uma das sete maravilhas do mundo antigo. Ver SALES, 2005: 108, nota 25. 
Anexo 1

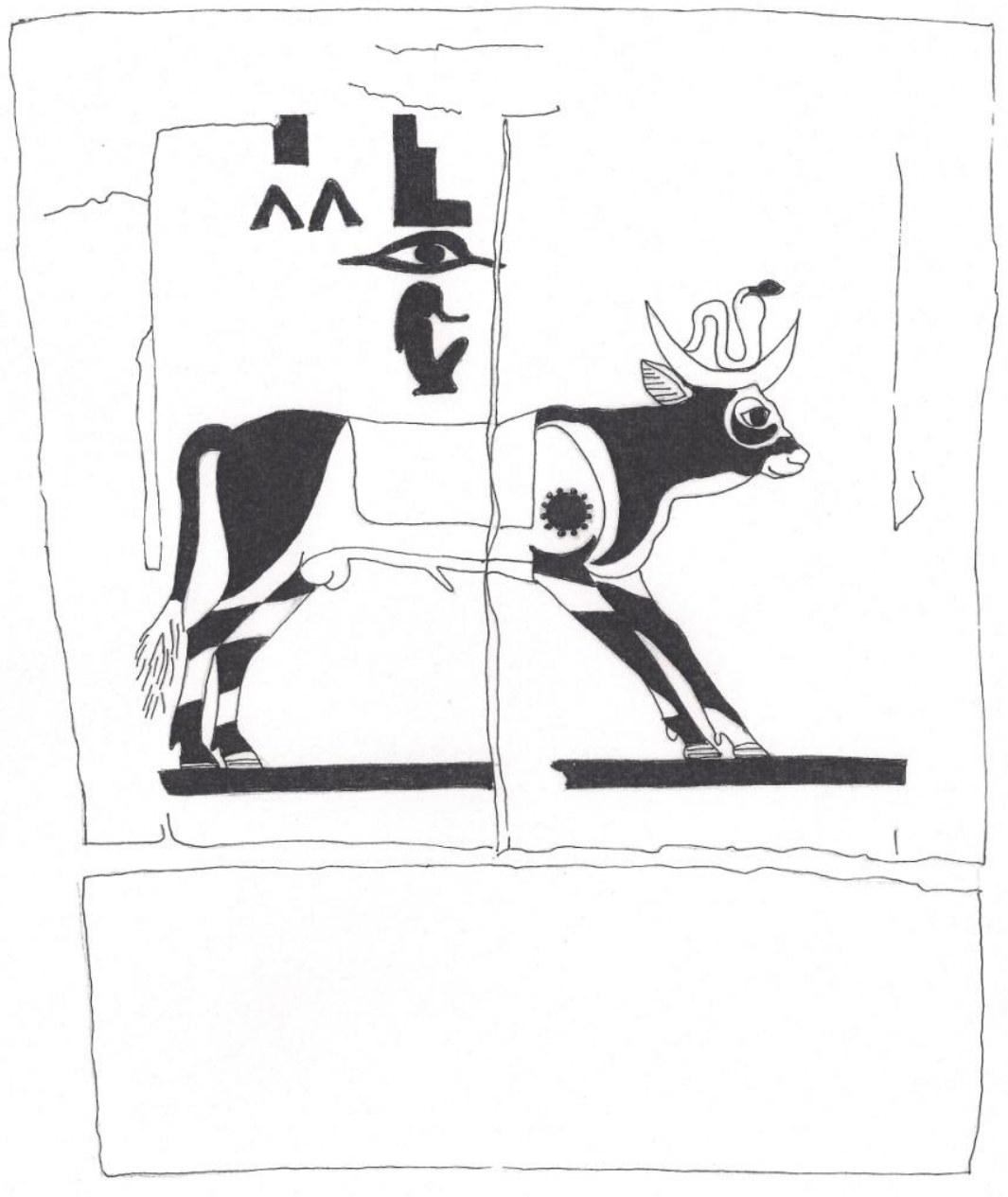

Figura 1 - Representação de User-Hap. Base do ataúde antropomórfico de Pabasa (período ptolemaico), Museu Nacional de Arqueologia (desenho do autor). 
Anexo 2

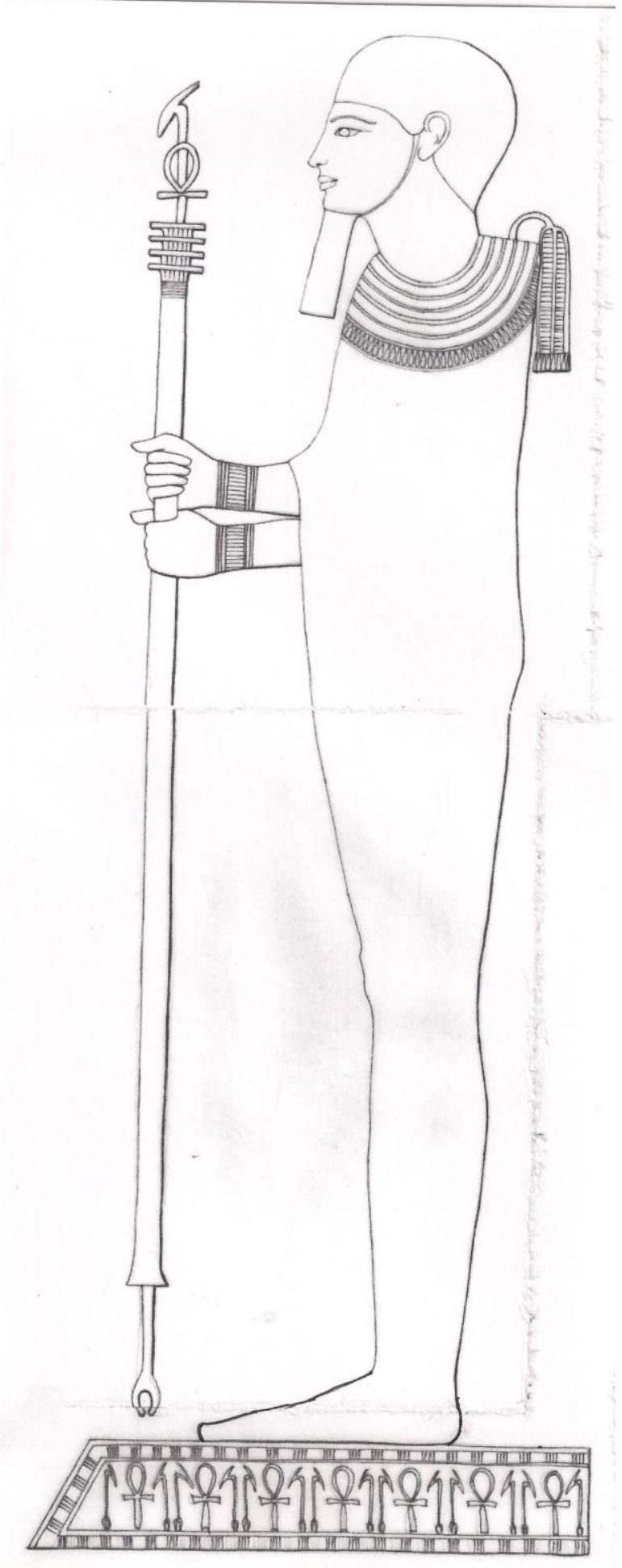

Figura 2 - Ptah, templo cenotáfio de Seti I em Abido, período ramséssida (desenho do autor). 


\section{Anexo 3}

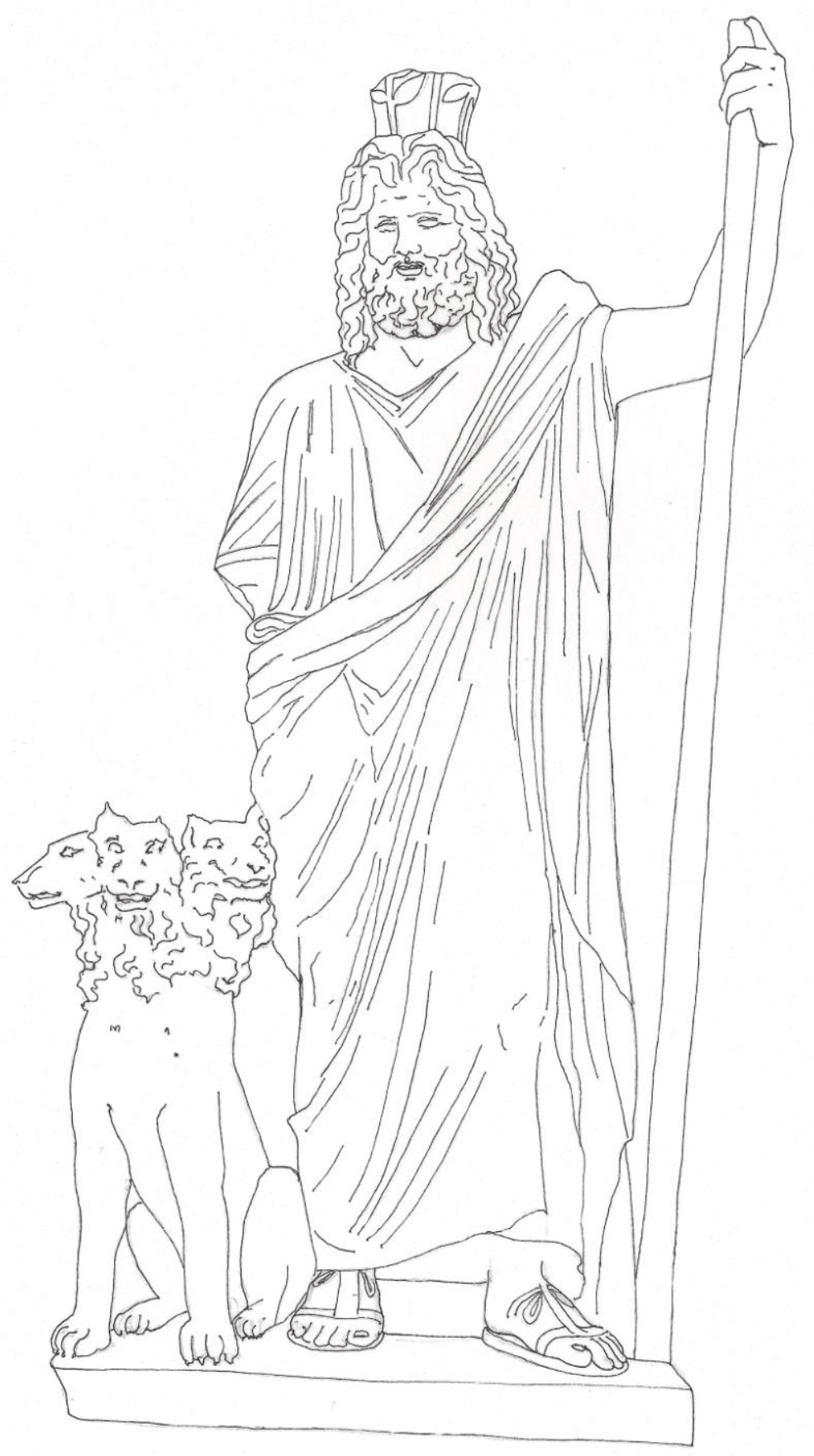

Figura 3 - Estátua de Serápis acompanhado por Cérbero. Encontrada em Cortina, a estátua reproduz a iconografia de uma estátua de culto alexandrina (desenho do autor). 


\section{REFERÊNCIAS BIBLIOGRÁFICAS}

\section{Fontes primárias}

APULEIO. O Burro de Ouro. Trad. Delfim Leão. Cotovia, Lisboa, 2007.

PLUTARCO. Ísis e Osíris. Fim de Século, Lisboa, 2001.

\section{Fontes secundárias}

ALFÖLDY, G. (1995). "Inscripciones, sacrificios y misterios: El santuario rupestre de Panóias / Portugal"; In. Madrider Mitteilungen, v. 36, pp. 252-258.

ALFÖLDY, G. (1997). "Die Mysterien von Panóias (Vila Real, Portugal)”; In. Madrider Mitteilungen, v. 38, pp. 176-246.

ALFÖLDY, G. (2002). "Panóias: o santuário rupestre”; In. CARDIM RIBEIRO, J., coord. Loquuntur saxa: Religiões da Lusitania. IMC, Lisboa, pp. 211-214.

BALLET, P. (1999). La vie quotidienne à Alexandrie. 331-30 avant J.-C.. Hachette, Paris.

BAGNALL, R., RATHBONE, D. (2008). Egypt: From Alexander to the Copts - An Archaeological and Historical Guide. The American University in Cairo Press, Cairo.

BERNAND, A. (1995). Alexandrie des Ptolémées. CNRS, Paris.

BRADY, T. (1935). The Reception of the Egyptian Cults by the Greeks (330-30 b. C.). University of Missouri, Missouri.

CASTIGLIONE (1978). "Nouvelles données archaeologiques concernant la génese du culte de Sarapis"; In. BOER, M., EDRIDGE, T. eds - Hommages a Maarten Vermaseren, v. 1. E. J. Brill, Leiden.

CHAUVEAU, M. (2000). A vida quotidiana no tempo de Cleópatra (180-30 a.C.). Livros do Brasil, Lisboa.

CHAUVEAU, M. (2001). Rhakôtis et la fondation d'Alexandrie; In. Égypte, Afrique \& Orient, n. 24, pp. 13-16.

FRASER, P. M. (1965). Current Problems concerning the early History of the Cult of Sarapis; In Opuscula Atheniensia, v. 5, pp. 23-45. 
LÓPEZ SALVÁ, M. (1992). Isis y Sarapis: diffusion de su culto en el Mundo Grecorromano; In. Minerva, v. 6, pp. 161-192.

RODRIGUES, N. S. (2001). “Alexandria”. ARAÚJO, L- M., dir. - Dicionário do Antigo Egipto. Editorial Caminho, Lisboa, pp. 46-48.

RODRÍGUEZ COLMENERO, A. (1999). O santuário rupestre galaico-romano de Panóias (Vila Real, Portugal): Novas achegas para a sua reinterpretação global. Ministério da Cultura, Lisboa.

SADEK, A. (1997). “Alexandrie, fille de Rakotis et fruit des relations égypto-grecques”; In. Le Monde Copte. Revue trimestrielle de la culture copte, $\mathrm{n}^{\mathrm{os}} 27-28$, pp. 7-20.

SALES, J. (2005). Ideologia e Propaganda Real no Egipto Ptolomaico (305-30 a.C.). Fundação Calouste Gulbenkian e Fundação para a Ciência e a Tecnologia, Lisboa.

SILVA, M. F. (2013). "On the trail of Alexandria's founding”; In. SOUSA, R., FIALHO, M., HAGGAG, M., RODRIGUES, N., eds. - Alexandria ad Aegyptum: The legacy of multiculturalism in Antiquity. CITCEM/CECHUC, Porto/Coimbra.

SOUSA, R., FIALHO, M., HAGGAG, M., RODRIGUES, N., eds. (2013). Alexandria ad Aegyptum: The legacy of multiculturalism in Antiquity. CITCEM/CECHUC, Porto/Coimbra.

SOUSA, R. (2009). Iniciação e Mistério no Antigo Egipto. Ésquilo, Lisboa. (2011). O Livro das Origens: A inscrição teológica da Pedra de Chabaka. Fundação Calouste Gulbenkian, Lisboa.

SOUSA, R., SILVA, J. edts (2013). Serápis nos confins do Império: O complexo sagrado de Panóias. Câmara Municipal de Vila Real e Direcção Regional de Cultura do Norte , Vila Real.

SOUSA, R., FIALHO, MARIA C; HAGGAG, MONA; RODRIGUES, NUNO S. eds. (2013). Alexandrea ad Aegyptum: The legacy of multiculturalism in Antiquity. Afrontamento, University of Porto, University of Coimbra, University of Alexandria, Porto, Coimbra, Alexandria.

STAMBAUGH, J. (1972). Serapis under the early Ptolemies, EPRO 25. E. J. Brill, Leiden.

STIEHL, R. (1963). The Origin of the Cult of Sarapis; In. History of Religions, 3/1, pp. 21 33. 
SWINNEN, W. (1973). Sur la politique religieuse de Ptolémée I ${ }^{\text {er }}$; In. Les syncrétismes dans les religions grecque et romaine. Colloque de Strasbourg (9-11 juin 1971). PUF, Paris, pp. 115-133. 